\title{
(6) OPEN ACCESS \\ Developing antitobacco mass media campaign messages in a low-resource setting: experience from the Kingdom of Tonga
}

\author{
C Sugden, ${ }^{1}$ P Phongsavan, ${ }^{2}$ S Gloede, ${ }^{1}$ S Filiai, ${ }^{3}$ V 0 Tongamana ${ }^{3}$
}

'Ministry of Health, Nuku'alofa, Tonga

2Sydney School of Public Health and the Charles Perkins Centre, The University of Sydney, Sydney, New South Wales, Australia

${ }^{3}$ Tonga Health Promotion Foundation, Nuku'alofa, Tonga

Correspondence to C Sugden, Ministry of Health, Nuku'alofa, Tonga; camsugden@gmail.com

Received 9 October 2015 Accepted 17 February 2016 Published Online First 11 March 2016
CrossMark

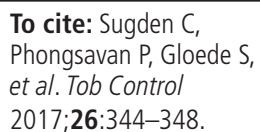

To cite: Sugden $C$, Phongsavan P, Gloede S et al. Tob Control 2017:26:344-348.

\section{ABSTRACT}

Tobacco use has become the leading cause of preventable death in Tonga, a small island nation in the South Pacific. One pragmatic and economical strategy to address this worrying trend is to adapt effective antitobacco mass media materials developed in highincome countries for local audiences. Using Tonga as an example, this paper shares the practical steps involved in adapting antitobacco campaign materials for local audiences with minimal resources, a limited budget and without the need for an external production team. The Tongan experience underscores the importance of an adaptation process that draws from evidence-based bestpractice models and engages local and regional stakeholders to ensure that campaign materials are tailored to the local context and are embedded within a mix of antitobacco strategies.

\section{BACKGROUND}

Mass media campaigns have become a key strategy in preventing and reducing tobacco use in highincome countries, among a mix of integrated strategies. ${ }^{1-3}$ Decades of research demonstrate that, if planned well, mass media campaigns can strengthen health literacy, shift broader social norms regarding tobacco use, establish a population-wide agenda for policy change and support a range of enforcement strategies. $^{1-5}$

Low and middle income countries (LMIC) with low populations face a number of challenges when creating evidence-based, high-impact antitobacco campaign materials. Developing mass media materials-including everything from exploratory research to concept development and productiontypically costs over US\$350 000 and takes at least 6 months. ${ }^{6}$ Moreover, media materials must include graphics, text and voice-overs that are carefully verified as accurate and appropriate by a range of health and marketing experts, often following months of debate and consensus-reaching. ${ }^{7} 8$ Finally, LMIC with low populations often lack the technical equipment and skills for mass media campaign design and implementation. ${ }^{69}$

One pragmatic and economical strategy to address these significant challenges is to adapt successful campaigns produced in high-income countries for use in LMIC. ${ }^{6-12}$ Multiple studies have shown that a range of advertisements, particularly those featuring strong graphic imagery, have performed 'consistently highly' when adapted for use in LMIC (ref. 9, p. 1). The adaptation process involves identifying high quality and relevant materials developed in other countries and requesting permission to tailor this content to the local context by developing local translations of text, including images of local people and settings, and adding other locally specific content. ${ }^{9}$ This allows for the development of evidence-based, highquality materials that are appropriate to the local context. Against this backdrop, planning for Tongan adaptations of antitobacco advertisements produced in Australia, the UK and the USA started in mid-2014.

This paper presents some of the practical steps involved in adapting antitobacco campaign materials for local audiences with minimal resources, a limited budget and without the need for an external production team. It is argued that the adaptation approach can result in considerable savings of cost and time in low-resource and low-population settings and may be considered a viable option in countries facing challenges similar to those in Tonga. The Tongan experience also underscores the importance of an adaptation process that draws from evidence-based best practice models and engages local and regional stakeholders to ensure that campaign materials are tailored to the local context and are embedded within a mix of antitobacco strategies. $^{9-14}$

\section{TOBACCO USE IN TONGA}

The Kingdom of Tonga is a small South Pacific island nation with just over 100000 residents spread across four major island groups. ${ }^{15}$ Tobacco use is a major cause of preventable death in Tonga and a leading contributor to the nation's alarming rise in non-communicable diseases (NCDs). ${ }^{16}$ Approximately $46 \%$ of males and $13 \%$ of females smoke in the Kingdom, with about $90 \%$ of this population smoking daily. ${ }^{16}$ Secondhand smoke is also of concern, with over a third of Tongans reporting that they have been exposed to secondhand smoke at least once during the previous week at home (39\%) and at work (32\%). ${ }^{16}$

Tonga ratified the WHO Framework Convention on Tobacco Control in 2005, prompting significant taxes on tobacco and the establishment of tobaccofree zones in public places. ${ }^{16}$ Despite these steps, research suggests that smoking is still an accepted social norm and that health literacy regarding the harms of tobacco use is poor, with $74 \%$ of Tongans in one survey believing that there is a safe level of cigarettes that can be smoked. ${ }^{17} 18$ The need for Tonga to improve tobacco-related health literacy and to strengthen policy and regulatory 
environments stresses the value of implementing an effective mass-media campaign for the local population.

\section{PRACTICAL STEPS IN ADAPTING THE ADS}

A number of considerations, informed by the vast literature base, proved vital in adapting a series of antitobacco ads in Tonga despite limited resources, a production team of just two individuals and a budget of \$A5000. They included: identifying an appropriate campaign to adapt with the help of selection criteria; partnering and engaging with a range of local, regional and international stakeholders; segmenting target audiences to align with local contexts with the aid of reliable and accurate data; planning and improvising throughout the production phase; and adjusting materials following feedback from key stakeholders and consumer pretesting with target audiences.

\section{Identifying an appropriate campaign to adapt}

The team was guided by the following questions when looking for campaigns to adapt: Is the campaign based on the latest and best evidence? Has it demonstrated effectiveness in promoting changes in knowledge, attitudes and behaviours among target audiences? Can it be adapted on a small budget and with few resources? How easily can it be tailored to the Tongan context and made suitable for Tongan audiences? Can permission to adapt the original material be granted by those who own the copyrights? Will the campaign complement and support other antitobacco strategies? ${ }^{6} 19$

On the basis of the answers to these questions, six TV ads were selected for adaptation in Tonga (see table 1). Each of these ads was well supported by empirical research, ${ }^{6} \quad \begin{array}{lll}11 & 12 & 20\end{array}$ and had been effectively adapted in over 10 low and middle income nations with limited resources and small production budgets. ${ }^{9}$ Sections of the ads that required adaptation were technically straightforward and could be easily tailored to the Tongan context if foreign actors appearing in the first and final few seconds of each ad were replaced with Tongans (see figure 1). Importantly, owing to an arrangement by the World Lung Foundation, LMICs like Tonga could be granted permission to adapt the advertisements without needing to pay licensing fees. Finally, the ads could accompany and support a number of other antitobacco strategies, including public education, cessation support services, smoke-free zones and tobacco taxes. ${ }^{6} 7$ In

Table 1 Initial TV ads adapted in Tonga

\begin{tabular}{|c|c|}
\hline Original advertisement & Tongan adaptation \\
\hline $\begin{array}{l}\text { Sponge (2007) } \\
\text { Cancer Institute NSW (Australia) } \\
\text { http://67.199.72.89/mmr/english/ad_sponge.html }\end{array}$ & https://vimeo.com/101585008 \\
\hline $\begin{array}{l}\text { Brain (1997) } \\
\text { Department of Health (Australia) } \\
\text { http://67.199.72.89/mmr/english/ad_brain.html }\end{array}$ & https://vimeo.com/92896299 \\
\hline $\begin{array}{l}\text { Lung (1997) } \\
\text { Department of Health (Australia) } \\
\text { http://67.199.72.89/mmr/english/ad_lungy.html }\end{array}$ & https://vimeo.com/92906662 \\
\hline $\begin{array}{l}\text { Artery, female version (1997) } \\
\text { Department of Health (Australia) } \\
\text { http://67.199.72.89/mmr/english/ad_artery.html }\end{array}$ & https://vimeo.com/92896336 \\
\hline $\begin{array}{l}\text { Artery, male version (1997) } \\
\text { Department of Health (Australia) } \\
\text { http://67.199.72.89/mmr/english/ad_artery.html }\end{array}$ & https://vimeo.com/92896257 \\
\hline $\begin{array}{l}\text { Heart (2003) } \\
\text { California Department of Health Services (USA) } \\
\text { http://67.199.72.89/mmr/english/ad_clinical.html }\end{array}$ & https://vimeo.com/101579518 \\
\hline
\end{tabular}

short, these six advertisements were evidence-based, effective, technically feasible, affordable, locally adaptable and could be embedded within an integrated strategy, making them a highly suitable option for a Tongan adaptation.

\section{Partnering and engaging with stakeholders}

A range of local and international stakeholders were sought to ensure that the Tongan adaptations were tailored to the local context and that the original intent of the campaign messages was not lost or misconstrued as a result of the adaptation. At the international level, advisors from the World Lung Foundation agreed to provide regular technical support and feedback, at no cost, to ensure that the Tongan adaptations were supported by the same medical research and marketing principles that guided similar adaptations in 10 LMIC countries. Local stakeholder engagement remained strong throughout the project. Regular face-to-face discussions and feedback sessions were conducted with a range of doctors, nurses, health promotion workers, members of the National Tobacco Control Subcommittee and heads of relevant health organisations throughout the preproduction and planning phases. This allowed the team to discuss local constraints and strengths, clarify appropriate settings to film the ads, recruit suitable actors, refine voice-over and text translations, and ensure that the ads would complement broader antitobacco strategies planned for the future.

\section{Segmenting target audiences}

Audience segmentation, which involves dividing a broader population into subgroups whose needs, experiences, attitudes and behaviours can be more specifically targeted, can improve the effectiveness of mass media campaigns. ${ }^{13} 2122$ Guided by data from the 2004 and 2014 WHO STEPS surveys, ${ }^{16}{ }^{23}$ it was decided to recruit actors that matched five possible target audiences: three male (18-24, 25-34 and 35-54) and two female (18-24 and 25-34). Female smokers 35 years and older were excluded on the basis of their relatively low smoking rates $(9 \%){ }^{16}$ Also, considering that $79 \%$ of smokers had unsuccessfully tried to quit in the past year, ${ }^{18}$ the ads would include a call to action that made smokers aware of community cessation support services that were to be developed by the Ministry of Health with the support of Quit Victoria.

\section{Planning and improvising throughout the production phase}

With a production crew of just two individuals, a small film kit and a budget of $\$ A 5000$, shooting and editing the ads required much planning and improvisation to simplify the technical requirements and workflow as much as possible. While a semiprofessional video camera was used, no audio was recorded and

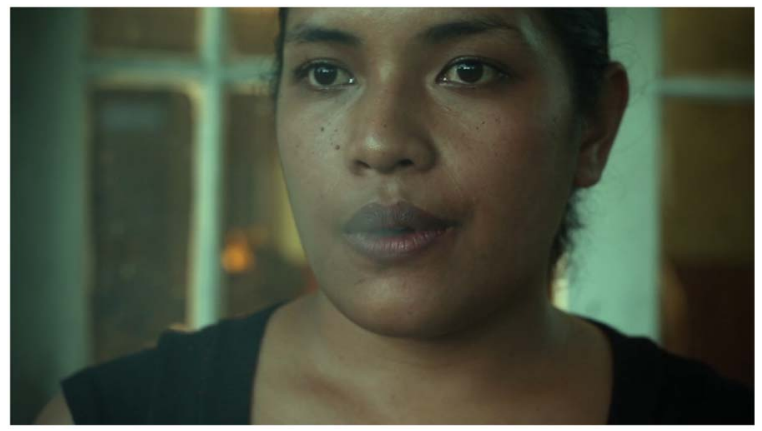

Figure 1 Foreign actors appearing in the original ads were replaced with Tongans. 
existing light sources emanating from street lamps, shops and cars were used instead of a professional lighting kit. The acting roles were very simple; accordingly, friends and family were invited to appear in each ad, with their time, travel and food expenses being compensated by the hour.

Translating the English voice-over and text into Tongan proved the most challenging and time-consuming aspect of the project. Medical terms such as 'stroke', 'paralyse', 'plaque', 'blood clots' and 'aorta', for example, needed to be both scientifically accurate and comprehensible to Tongan audiences. Metaphors and descriptive words such as 'sponge' and 'air sacs' also required careful attention and multiple revisions. Tongan translations were provided by two individuals for comparison: a Tongan linguist at Auckland University and a local health professional who had experience in translating government documents and reports. Text and voice-overs for each ad were then backtranslated by 15-20 individuals, including members of the target audience and a number of key stakeholders. Inconsistencies or areas of ambiguity were identified, discussed and adjusted. The translation process continued over a period of weeks until consensus was reached across key stakeholders.

\section{Adjusting materials following stakeholder feedback and pretesting}

Draft versions of the Tongan ads were presented to key stakeholders and, based on their feedback, campaign goals and objectives were refined, significant changes were made to Tongan translations and a decision was made to develop additional ads from the USA ${ }^{24} 25$ and the $\mathrm{UK}^{26}$ that highlighted the harms of secondhand smoke, particularly on children (see figure 2). In addition, on the basis of its strong performance in other countries, an advertisement containing highly graphic imagery was also adapted, ${ }^{27}$ bringing the total number of Tongan adaptations to 10 (see table 2).

Consumer field pretesting of the ads was conducted by the Tongan team with technical advice provided by a research group from Cancer Council Victoria, an independent non-profit organisation that advises various Australian and international groups on cancer-related issues. ${ }^{28}$ The Tongan team partnered with this research group because of their experience in leading a much larger 10-country study funded by the World Lung Foundation. ' Using the same sampling and data collection methods used in the 10 -country study, ${ }^{9}$ approximately 140 individuals from the target audience were included in the pretest, consisting entirely of Tongans who had been smoking for 1 year or more divided by gender (male/female), location (urban/rural) and age (18-24/25-34 years). ${ }^{29}$ A larger proportion of males participated in the study, reflecting their higher smoking rates

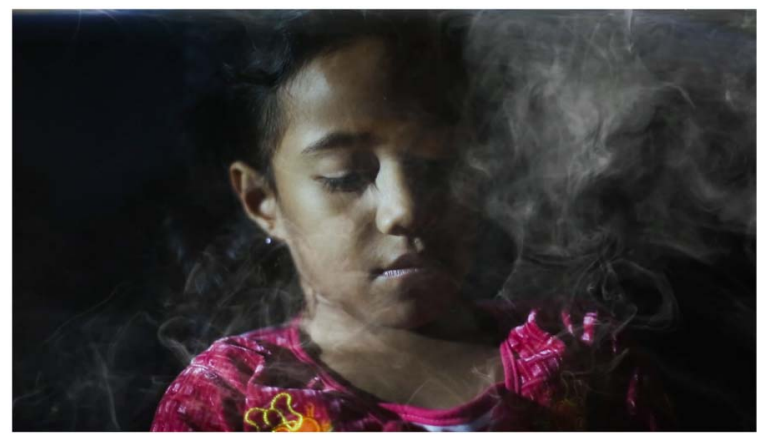

Figure 2 Secondhand smoke ads focused on exposure to children in cars and homes.
Table 2 Ads produced following stakeholder feedback

\begin{tabular}{|c|c|}
\hline Original advertisement & Tongan adaptation \\
\hline $\begin{array}{l}\text { Smokefree Home (2013) } \\
\text { National Health Service (UK) } \\
\text { https://www.youtube.com/watch?v=PMBPB3vh34c }\end{array}$ & $\begin{array}{l}\text { https://vimeo.com/ } \\
101578446\end{array}$ \\
\hline $\begin{array}{l}\text { Smokefree Car (2013) } \\
\text { National Health Service (UK) } \\
\text { https://www.youtube.com/watch?v=0EzNn1CPCJw }\end{array}$ & $\begin{array}{l}\text { https://vimeo.com/ } \\
101579022\end{array}$ \\
\hline $\begin{array}{l}\text { Cigarettes are Eating You Alive (2006) } \\
\text { The New York City Department of Health and Mental } \\
\text { Hygiene (USA) } \\
\text { http://67.199.72.89/mmr/english/ad_eating.html }\end{array}$ & $\begin{array}{l}\text { https://vimeo.com/ } \\
119309755\end{array}$ \\
\hline $\begin{array}{l}\text { Cigarettes are Eating Your Baby Alive (2007) } \\
\text { The New York City Department of Health and Mental } \\
\text { Hygiene (USA) } \\
\text { http://67.199.72.89/mmr/english/ad_eatingbaby.html }\end{array}$ & $\begin{array}{l}\text { https://vimeo.com/ } \\
119309672\end{array}$ \\
\hline
\end{tabular}

compared to females in Tonga. ${ }^{16}$ Only participants who could read and write in Tongan were included in the pretest, and individuals who had worked in health promotion, marketing research, advertising or the tobacco industry were excluded from recruitment. Refreshments and a \$10 incentive were provided to all participants.

To compare a variety of antismoking messages and advertisement styles, three additional ads from Australia, New Zealand and Tonga were added to the pretest set: Zita, Crayons and Cough. ${ }^{29}$ No adjustments were made to these three ads apart from adding Tongan subtitles for English-spoken sections of Zita and Crayons. Finally, to avoid any bias stemming from the order in which the ads were presented, half of all participants viewed the spots in reverse order. Recruitment and data collection for the field pretest were undertaken by the Tongan team, while data analyses and reporting were completed by the Cancer Council Victoria research team.

Analysis of the pretest results revealed that while all adapted ads performed strongly across measures of concern and promoted behaviour change, three demonstrated the most potential and required no changes according to the researchers: Baby Alive, Adult Alive and Heart. ${ }^{29}$ Ads that featured more complex health messages (eg, Artery and Brain) or which used non-graphic imagery (eg, Crayons and Cough) performed relatively weaker.

Pretest data also indicated that secondhand smoke ads may be more effective than individual health-threat ads in Tonga. ${ }^{29}$ Importantly, like many Pacific Islanders, Tongans typically live in extended family environments. ${ }^{15}$ Indeed, $75 \%$ of participants pretested lived with a child. These findings suggested that broadcasting the secondhand smoke ads (Baby Alive and Heart) might have the greatest potential in motivating quit attempts among Tongans and in reducing smoking behaviours that result in harmful passive exposure.

The consumer pretesting phase was the first point in the adaptation process in which external support was requested by the Tongan team. Additional funding from the Australian Department of Foreign Affairs and Trade allowed the team to partner with Cancer Council Victoria to guide this highly technical aspect of the project. Nevertheless, this donor-funded component was a discrete late-stage aspect of the adaptation process, allowing the Tongan team to maintain a high level of ownership and control over the timing and nature of the campaign.

\section{LESSONS LEARNT}

Some aspects of the adaptation process could have been improved. The project would have benefited from developing 
deeper insight into local audiences and local circumstances prior to ad production. Owing to the lack of funding to conduct primary research with local audiences and stakeholders, the team could only rely on secondary research from international studies that did not necessarily reflect the Tongan context ${ }^{911}$ or on local data that lacked a specific focus on tobacco use. ${ }^{16} 18$ Accordingly, the team had to produce a range of ads on a small budget and apply for additional funding for pretesting only once they demonstrated promise to stakeholders and donors. This approach carried the obvious risk that the communication strategies and messages chosen by the team might have proven inappropriate to the local context. Were more funding and resources available for formative research, the team could have reduced this risk.

In addition, delineating specific persons to campaign strategy, creative production, media relations, policy advocacy, stakeholder management, monitoring and evaluation, and financing would have improved planning and efficiency. As is often the case in low-resource settings, the small team was required to take on multiple roles and adjust their expectations until more funding and technical support could be secured.

\section{NEXT STEPS}

The decision to adapt mass media materials developed elsewhere has saved costs and time in Tonga's low-resource and low-population setting. Other Pacific countries facing comparable challenges may consider adopting a similar approach.

Tonga will launch a 5-year National NCD Strategy in May 2016. Owing to the strong performance of a range of antitobacco ads now adapted for the Kingdom, ${ }^{29}$ Tonga now has sufficient evidence-based mass media campaign materials for the duration of this strategy. The Australian Government has funded a series of 6-week mass media bursts that will complement the airing of the antitobacco TV ads with billboards, posters, bus signs, radio spots and social media across the Kingdom over the 5 -year initiative.

Research shows that antitobacco mass media campaigns are more effective when delivered as part of a mix of integrated strategies, including cessation support services, school education programmes, community workshops, bans on tobacco advertising, smoke-free areas, tobacco taxes and prominent health warnings on cigarette packaging. ${ }^{1-5} 30-33$ In addition, health threat campaigns that target adults have been found to be effective in driving reductions in youth uptake, ${ }^{34}$ especially when underpinned by appropriate youth engagement and price control strategies. ${ }^{35}$ Imbedding the delivery of the Tongan ads within the National NCD Strategy and its corresponding governance

\section{What this paper adds}

- Mass media campaigns can contribute to reducing tobacco use in low and middle income South Pacific countries like Tonga.

- Adapting mass media materials developed in high-income countries can result in considerable savings of cost and time in low-resource and low-population settings.

- Using Tonga as an example, this paper shares the practical steps involved in adapting antitobacco campaign materials for local audiences with minimal resources, a limited budget and without the need for an external production team. mechanisms ensures that the ads have sustainable multiyear funding and are integrated within a range of strategies.

A longitudinal pre-post study will evaluate the impact of the campaign in reaching target audiences, raising awareness, shifting attitudes and changing smoking behaviours. Rigorous measuring and reporting on the impact of the campaign will be critical to ensure that lessons are learnt and important adjustments are made as the campaign progresses.

Acknowledgements The authors acknowledge the contribution of Dr 'Ofa Tukia for supervising the Tongan adaptation initiative, and Tupou Tuilautala for his role in the sampling and data collection aspects of pretesting. The authors also acknowledge World Lung Foundation for brokering licenses for local adaptations, the Tonga Health Promotion Foundation for supporting the initial production of the ads, the Tonga Ministry of Health for assisting with pretesting and campaign strategy, the Australian Department of Foreign Affairs and Trade for funding research and campaign implementation components, and Cancer Institute NSW, the Department of Health (Australia), the National Health Service (UK), The New York City Department of Health and Mental Hygiene (USA) and the California Department of Health Services (USA) for agreeing to provide footage for local adaptation. Finally, the authors are grateful to Tom Carroll, Tahir Turk and Irina Morozova for providing technical advice during production and to Megan Bayly and Sarah Durkin from Cancer Council Victoria for leading consumer pretesting.

Contributors CS and SG coordinated the planning and production of the Tongan antitobacco TV ads with the assistance of SF and VOT. CS led the writing of the manuscript while PP supervised and contributed to the structure and editing. SG also contributed to the structure and editing. All authors contributed to drafts of the paper and approved the final version of the manuscript.

Funding The pretesting, broadcast and evaluation of the Tongan ads was funded by the Australian Department of Foreign Affairs and Trade.

Competing interests None declared.

\section{Patient consent Obtained.}

Provenance and peer review Not commissioned; externally peer reviewed.

Open Access This is an Open Access article distributed in accordance with the Creative Commons Attribution Non Commercial (CC BY-NC 4.0) license, which permits others to distribute, remix, adapt, build upon this work non-commercially, and license their derivative works on different terms, provided the original work is properly cited and the use is non-commercial. See: http://creativecommons.org/ licenses/by-nc/4.0/

\section{REFERENCES}

1 National Cancer Institute. The role of the media in promoting and reducing tobacco use. Tobacco Control Monograph No 19. NIH Pub No 07-6242. Bethesda, MD: US Department of Health and Human Services, National Institutes of Health, National Cancer Institute, 2008

2 Bala M, Strzeszynski L, Cahill K. Mass media interventions for smoking cessation in adults. Cochrane Database Syst Rev 2008;(1):CD004704.

3 Durkin S, Brennan E, Wakefield M. Mass media campaigns to promote smoking cessation among adults: an integrative review. Tob Control 2012;21:127-38.

4 Eriksen M, Mackay J, Schluger N, et al. The tobacco Atlas (No. Ed. 5). American Cancer Society, 2015. http://3pk43×313ggr4cy0lh3tctjh.wpengine.netdna-cdn.com/ wp-content/uploads/2015/03/TA5_2015_WEB.pdf (accessed 17 Nov 2015).

5 Hornik R. Public health communication: evidence for behavior change. Mahwah, NJ: Lawrence Erlbaum, 2002.

6 Cotter T, Perez D, Dunlop S, et al. The case for recycling and adapting anti-tobacco mass media campaigns. Tob Control 2010;19:514-17.

7 Cotter T, Hung WT, Perez D, et al. Squeezing new life out of an old sponge: how to modernise an anti-smoking media campaign to capture a new market. Aust N Z J Public Health 2011;35:75-80.

8 Jamrozik K. Population strategies to prevent smoking. BMJ 2004;328:759-62.

9 Wakefield M, Bayly M, Durkin S, et al. Smokers' responses to television advertisements about the serious harms of tobacco use: pre-testing results from 10 low- to middle-income countries. Tob Control 2013;22:24-31.

10 Mullin S, Prasad V, Kaur J, et al. Increasing evidence for the efficacy of tobacco control mass media communication programming in low-and-middle-income countries. J Health Commun 2011;16(Suppl 2):49-58.

11 Murukutla N, Bayly M, Mullin S, et al. Male smoker and non-smoker responses to television advertisements on the harms of secondhand smoke in China, India and Russia. Health Educ Res 2015;30:24-34.

12 Perl R, Stebenkova L, Morozova I, et al. Mass media campaigns within reach: effective efforts with limited resources in Russia's capital city. Tob Control 2011;20:439-41. 
13 French J, Blair-Stevens C, McVey D, et al. Social marketing and public health: theory and practice. Oxford: Oxford University Press, 2010.

14 Noar SM. A 10-year retrospective of research in health mass media campaigns: where do we go from here? J Health Commun 2006:11:21-42.

15 Kingdom of Tonga Statistics Department. Population census 2011. Nuku'alofa, Tonga: Government of Tonga, 2011.

16 World Health Organization and Tongan Ministry of Health. Kingdom of Tonga NCD Risk Factors STEPS Report. Suva, Fiji: World Health Organization, 2014.

17 Crime Statistics Office. Total number of people charged with smoking in public places in the Kingdom, 2010-2013. Nuku'alofa, Tonga: Crime Statistics Office, 2014.

18 Tongan Ministry of Health. Non-communicable diseases, what do we know in Tonga: knowledge, attitudes, and practices on NCDs in Tonga. Nuku'alofa, Tonga: Tongan Ministry of Health and the Australian Department of Foreign Affairs and Trade, 2014

19 The Mass Media Taskforce. Guidelines for planning and implementing mass media advertising campaigns. New York: World Lung Foundation, 2008. http://67.199.72. 89/mmr/english/files/en_guidelines.pdf (accessed 15 May 2015).

20 Myers P, Blackmore D. Evaluation of the 2011 NPAPH tobacco social marketing campaign. Melbourne, VIC: The Social Research Centre, 2011. http://www.quitnow. gov.au/internet/quitnow/publishing.nsf/Content/A61C 40086BCE07F8CA257 A0D001F1207/\$File/NTC\%202011\%20Evaluation\%20Report\%20FINAL.pdf (accessed 14 Oct 2015).

21 Dibb S. Criteria guiding segmentation implementation: reviewing the evidence. J Strateg Mark 1999;7:107-29.

22 Maibach EW, Weber D, Massett $\mathrm{H}$, et al. Understanding consumers' health information preferences: development and initial validation of a brief screening instrument. J Health Commun 2006;11:717-36.

23 World Health Organization and Tongan Ministry of Health. Kingdom of Tonga NCD risk factors STEPS report. Suva, Fiij: World Health Organization, 2004.

24 California Department of Public Health. 'Clinical' [TV advertisement], 2003. http:/l nccd.cdc.gov/MCRC/Apps/SearchDetails.aspx?CatalogID=1242\&lFS=92967 (accessed 15 Sep 2015)

25 The New York City Department of Health and Mental Hygiene. 'Cigarettes are Eating Your Baby Alive' [TV advertisement]. 2007. http://67.199.72.89/mmr/english/ ad_eatingbaby.html (accessed 20 Feb 2015).
26 National Health Service. 'Smokefree homes and cars 2013' [TV advertisements]. 2013. http://resources.smokefree.nhs.uk/news/campaigns/smokefree-homescars-2013/ (accessed 1 Sep 2014).

27 The New York City Department of Health and Mental Hygiene. 'Cigarettes are Eating You Alive' [TV advertisement]. 2007. http://www.worldlungfoundation.org/ht/ d/sp/i/14745/pid/14745 (accessed 20 Feb 2015).

28 Cancer Council Victoria. 'About Us' [Website]. 2016. http://www.cancervic.org.au/ about (accessed 6 Jan 2016).

29 Bayly M, Durkin S. Tongan anti-smoking television advertising study: quantitative analyses and summary report. Melbourne, VIC: Cancer Council Victoria, 2015.

30 World Health Organization. WHO report on the global tobacco epidemic, 2013: enforcing bans on tobacco advertising, promotion and sponsorship. Geneva, Switzerland: World Health Organization, 2013. http://apps.who.int/iris/bitstream/ 10665/85380/1/9789241505871_eng.pdf (accessed 6 Sep 2015).

31 Brennan E, Durkin SJ, Cotter T, et al. Mass media campaigns designed to support new pictorial health warnings on cigarette packets: evidence of a complementary relationship. Tob Control 2011:20:412-18.

32 Carroll T, Rock B. Generating Quitline calls during Australia's National Tobacco Campaign: effects of television advertisement execution and programme placement. Tob Control 2003;12: ii40-4.

33 Tan N, Wakefield M, Freeman J. Changes associated with The National Tobacco Campaign: results of the second follow-up survey. In: Hassard K, ed. Australia's National Tobacco Campaign: evaluation report volume two. Commonwealth Department of Health and Aged Care. Canberra, ACT: Commonwealth of Australia, 2000. http://www.health.gov.au/internet/main/publishing.nsf/Content/healthpubhlth-publicat-document-tobccamp_2-cnt.htm (accessed 1 Sep 2015).

34 White $\mathrm{V}$, Tan N, Wakefield $\mathrm{M}$, et al. Do adult focused anti-smoking campaigns have an impact on adolescents? The case of The Australian National Tobacco Campaign. Tob Control 2003;12:23-9.

35 US Department of Health and Human Services. Preventing tobacco use among youth and young adults: a report of the Surgeon General. Atlanta, GA: Department of Health and Human Services, Centers for Disease Control and Prevention, National Center for Chronic Disease Prevention and Health Promotion, Office on Smoking and Health, 2012. 